\section{de Winter Electrocardiogram Pattern Due to Vasospastic Angina}

Hirohiko Ando, PhD; Masahiro Shimoda, MD; Hirofumi Ohashi, MD; Yusuke Nakano, PhD; Hiroaki Takashima, PhD; Tetsuya Amano, PhD

A 64-year-old woman with a smoking history of 20 pack-years presented to the emergency department with chest pain lasting $1 \mathrm{~h}$ in the morning. She had experienced a similar symptom in the morning before. The result of an initial troponin I test was normal (it increased in subsequent tests). Electrocardiogram (ECG) showed upsloping ST-segment depression and tall, peaked T waves in leads V2-V5, consistent with typical de Winter ECG pattern (Figure). Echocardiography demonstrated a decreased anteroseptal wall motion. Emergency coronary angiography revealed severe stenosis in the proximal left anterior descending artery (LAD), which resolved after intracoronary injection of isosorbide dinitrate. Optical frequency domain imaging of the lesion demonstrated a normal 3-layered vascular structure without advanced plaque. Consequently, we determined vasospastic angina (VSA) as the cause of acute coronary syndrome and treated using calcium-channel blockers. Subsequent ECGs are shown in Supplementary Figure.

The de Winter ECG pattern was first described in 2008 as an equivalent of ST-elevation myocardial infarction due to proximal LAD occlusion. ${ }^{1}$ It is characterized by an upsloping ST-segment depression at the J-point in leads V1-6 that continues into a tall, positive symmetrical $\mathrm{T}$ wave. Despite the associated high mortality $(27 \%)$, this unique ECG pattern is still poorly recognized. ${ }^{2}$ Previous studies reported that the de Winter ECG pattern was highly relevant to plaque-related thrombotic events. To our knowledge, this is the first report showing the de Winter ECG pattern in a VSA patient. Recognition of this challenging ECG is vital for implementing a rapid reperfusion strategy.

\section{Disclosures}

T.A. is a member of Circulation Journal' Editorial Team.

\section{References}

1. de Winter RJ, Verouden NJ, Wellens HJ, Wilde AA. A new ECG sign of proximal LAD occlusion. $N$ Engl J Med 2008; 359: 2071-2073.

2. de Winter RW, Adams R, Amoroso G, Appelman Y, Ten Brinke L, Huybrechts B, et al. Prevalence of junctional ST-depression with tall symmetrical T-waves in a pre-hospital field triage system for STEMI patients. J Electrocardiol 2019; 52: 1-5.

\section{Supplementary Files}

Please find supplementary file(s);

http://dx.doi.org/10.1253/circj.CJ-20-0519

Received May 25, 2020; revised manuscript received June 12, 2020; accepted June 19, 2020; J-STAGE Advance Publication released online July 31, 2020 Time for primary review: 14 days

Department of Cardiology, Aichi Medical University, Nagakute, Japan

Mailing address: Hirohiko Ando, PhD, Department of Cardiology, Aichi Medical University, 1-1 Yazakokarimata, Nagakute 480-1195, Japan. E-mail: anhiro@aichi-med-u.ac.jp

All rights are reserved to the Japanese Circulation Society. For permissions, please e-mail: cj@j-circ.or.jp ISSN-1346-9843

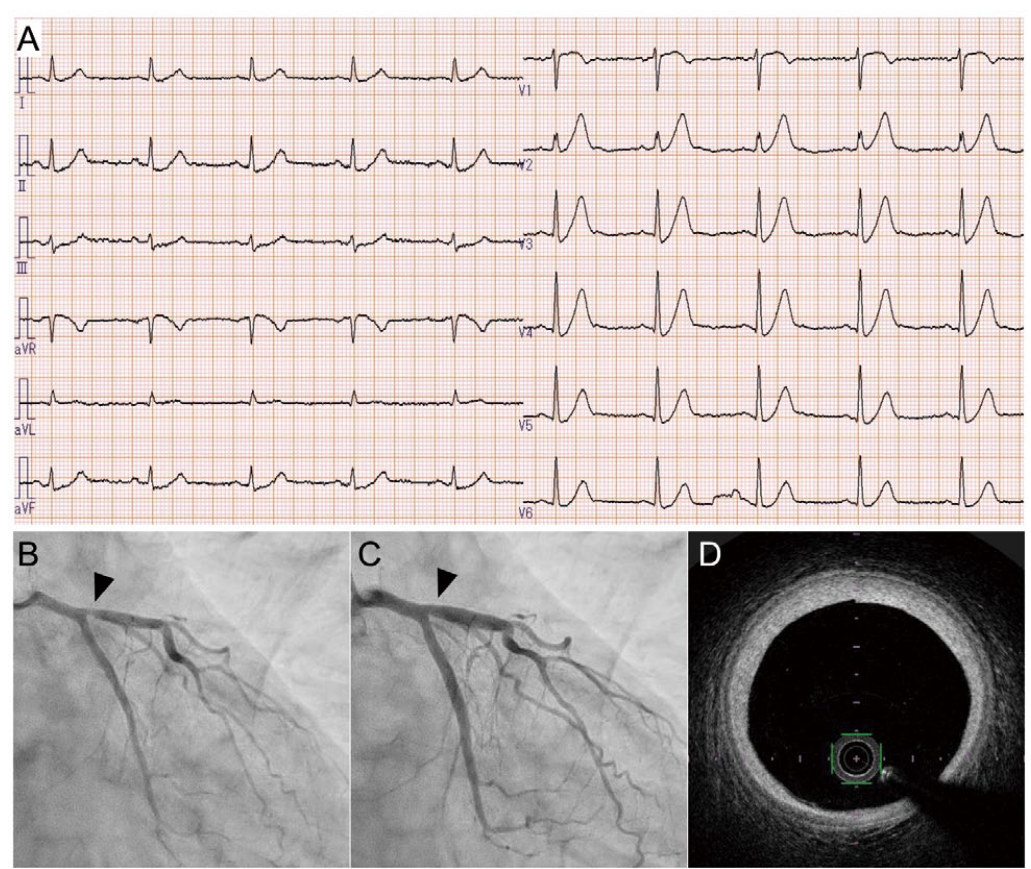

Figure. (A) Electrocardiogram on arrival demonstrated typical de Winter electrocardiogram pattern. (B) First coronary angiography. (C) Coronary angiography after injection of isosorbide dinitrate. (D) Optical frequency domain imaging at culprit lesion. 